\title{
Might we be Calling Problems Seen in Autism Spectrum Conditions: 'Poor Theory of Mind,' when Actually they are Related to Non-Generalised 'Object Permanence'?
}

\author{
Wenn B. Lawson ${ }^{1, *}$ and Brynn A. Dombroski ${ }^{2}$ \\ ${ }^{1}$ Department of Disability University of Birmingham, UK \\ ${ }^{2}$ Department of Anatomical Sciences and Neurobiology, University of Louisville School of Medicine, USA
}

\begin{abstract}
Autism spectrum conditions (ASC) and the delayed development of object permanence is often not questioned, and is rarely understood. The following paper attempts to explore this idea and suggests reasons for why such development is delayed and the possibility that certain difficult behaviours seen in children with ASC are less likely to be connected to having poor theory of mind and more connected to lacking generalized concepts of object permanence.
\end{abstract}

Keywords: Autism Spectrum Conditions, Theory of Mind, Object Permanence, Challenging Behaviour.

ASC occurs in individuals who, according to the DSM-5 (2013) [1], are assessed using two criteria:

- difficulties with the social and communication domain

- $\quad$ difficulties due to a restricted repetitive interest and behaviour domain.

The latter category could also be considered as being 'extremely single-minded' and/or having 'deeply focused attention', (Belmonte, 2000 [2]; Dern, 2008 [3]; Harmon, 2010 [4]; Lawson, 2000 [5]; Lawson, 2011 [6]; Murray, 1992 [7]; Murray, Lesser \& Lawson, 2005 [8]. As well as the above, ASC individuals may have sensory dysphoria and specific characteristics peculiar to them such as language issues, cognition difficulties, motor and movement issues and/or other specifiers. Symptoms must be present in early childhood or occur when demand exceeds capacity and must lead to impairment [1].

This paper suggests, due to the above, children with ASC have difficulties with their understanding of (among other things): what's here, what's now, what is permanent, and so on. It explores how this might impact upon the development of object permanence.

\section{CHALLENGING BEHAVIOUR (STRESS SUPPORT NEEDS)}

Children with ASC will find it difficult to maintain eye contact, difficult to identify emotions of self or other and

*Address correspondence to this author at The School of Education, University of Birmingham, Edgbaston, Birmingham, B15 2TT, UK;

E-mail: lawson_wendy@hotmail.com,wenbe@bigpond.com difficult to generalize concepts. This 'failure' to attend to several things simultaneously has often been misinterpreted as having 'poor theory of mind' (ToM) or poor ability to put themselves into 'another's shoes'. The development of object permanence (OP) (see below) implies a child needs to attend to multiple stimuli. In ASC this is difficult, outside of interest [5, 6 , 7]; Lawson, 2012 [9].

\section{OBJECT PERMANENCE (OP)}

OP implies that, at a certain age, a child's sensory and motor contributions to their cognitive understanding enables them to appreciate that an object can still be present and available (permanent) even when it can't be seen (e.g., lying beside you but hidden beneath a blanket) (Bailargeon, and DeVos, (1991) [10]; Bjorne, 2007 [11]). This awareness occurs in neurotypical (non-autistic) infants between the ages of 4 and 8 months (McLeod, 2010 [12]. Before this:

'When they are very young babies they don't give it a second thought when their mum and dad walk away from them. By five or six months old, though, babies will often fuss and cry when their parents attempt to leave them, believing that they have disappeared. It can take a few more months for them to understand that while they may not be able to see their mum, she still exists. This ability is called 'object permanence' (Grace, 2012. p.1 [13]).

Whether the person, object or event is in view or hidden from view, ASC individuals may not discern the fuller context of OP. For example, two girls with ASC (a 4-year-old and a 7-year-old) might know that their drink bottles are in their lunch bag, even when they can't see 
them, BUT, they don't seem to know that Mummy (or some other person/thing/event) is still there (or occurring), just not within their view.

We propose that this is due to a lack of "big picture" thinking which requires a full range of cognitive and sensorimotor skills to work synchronously within the brain, to determine, "where am I?" and "where is it?" especially in regards to object permanence and generalization.

Could it be these two girls (and other individuals) with ASC are lacking in a more generalized understanding of OP? Could failure of ToM tasks actually be explained by a lack in OP? If so, it explains so much of the fear and possibly subsequent challenging behaviour (stress support needs) we see in children with ASC.

So, what might it mean for children with ASC who fail to comprehend OP, especially when it's related to people, emotions, places, time and so on? For example, children with ASC may understand that even though they can't 'see' their drink bottle, they know that Mummy placed it into their lunch bag and its 'permanence' is not in question. But, when it comes to transferring this idea and generalizing the understanding to other aspects of daily life, the child with ASC may have huge difficulty. This paper hints at some of these difficulties, the reasons for them and potential remedies.

\section{Emotion, Behaviour Belief}

In correspondence with Dombroski, Lawson stated, "If we don't look at the issue behind the behavior (when is behaviour not behaviour?), what tends to happen is a battle irrupts and conflict ensues. Rather than join the war, we need to diffuse the battle."

In response to Lawson's inquiry of the cause behind the behavior, Dombroski posited, "anger and sadness are an 'expression' of the individual's current emotion. This may not always be 'intentional behavior' but rather, a 'biological response' to the neurochemical change in the brain due to a change in the environment." Dombroski's stance is supported by earlier findings shared by Lawson (2011) [6], Parrot (2001) [13] and LeDoux (1998) [15]. Often times, an expression of negative emotion is due to a lack of cognitive ability to logically reason through the change in the environment and adapt as necessary. For example, in the case of object permanence, when a parent plays peek-a-boo with an infant and the infant cries because he/she can no longer see his/her parent vs. the infant giggling and trying to find the parent. The change in the environment was the parent seeming to disappear (lack of object permanence). The infant's immediate reaction to the disappearance of his/her parent was fear and sadness expressed through crying. Once the infant has developed the cognitive ability to understand that his/her parent is still there, but hiding (development of object permanence), the infant's immediate reaction to this is to giggle and look for the parent.

A change in the infant's neurocognitive abilities (including sensory/motor connections) had to take place in order for the child to understand that the parent was still present $[9,11,12]$. However, in ASC, when considering the sensory and motor connections needed for the broader more generalized understanding of $\mathrm{OP}$, this process of cognitive development requires the infant to hold two (or more) concepts simultaneously: the feeling state and possible various reality states (e.g., I'm sad because Mummy left me, but she is only in the garden and she is coming back inside soon. She only left for a short time). This type of reasoning is very difficult to do for ASC children, who find shifting attention no easy task and who have a tough time reading social situations (Klin, et al. 2003, [17]).

$\mathrm{OP}$ is the result of: knowing (via a variety of connecting states) that an object still exists, even if it is hidden. It requires the ability to form a mental representation (i.e., a schema: See, Young, Klosko \& Weishaar $(2003,[18]$ of the object/event/person and so on (e.g., $[12,17])$.

'Schemata represent units of knowledge about everything individuals experience. Schemata become theories about reality. These theories not only affect the way information is interpreted, thus affecting comprehension, but also continue to change as new information is received' (http://www.csus.edu/indiv/g/ gipej/teaparty.pdf) [19].

\section{OBSERVATION}

ASC female child, aged 4 years came to stay with her grand-parents. Child was playing hide-and-go-seek with her 7-year-old sister. As soon as there were no signs that AJ (her sister) was around, the 4-year-old began to scream intensely with utter conviction that $A J$ was gone. Her feelings of abandonment and fear were 
obvious and it took some convincing to help her believe AJ wasn't gone, just hiding (not visible). The grandparents watched the 4-year-old repeat this experience over and over again. It was very upsetting for them and awful for her. This child was fully verbally able and very intelligent. It was not her intelligence that was limiting her from understanding the concept of this game; it was how she was learning to play this game versus how she learns best that was limiting her from understanding how to play the game.

In many cases with both neurotypical (NT) and ASC, the child is developmentally delayed because he/she is lacking the cognitive ability to logic and reason through a change in his/her environment. However, it seems that the more the child 'connects' with his/her environment through interest, the less time it will take for OP concepts to form [6, 9].

Cognitive abilities develop naturally, but in many cases, not fully (BA Dombroski, personal communication, July 26,2014$)$. This is why there is so much variation in learning styles. Some areas of the brain are more or less developed than others causing apparent strengths and weakness in visual learning, auditory learning, or kinesthetic learning (BA Dombroski, personal communication, July 26, 2014). Developmental deficiencies in vision or hearing directly impede an individual's ability to learn. This is why basic sensory and motor processing must also be considered in regards to identifying to root cause of an individual's behavior (BA Dombroski, personal communication, July 26, 2014)." Dombroski's view is supported by nonbiased research conducted by Björne (2007).

\section{TOM, EMPATHY OR OP}

In the past researchers have failed to appreciate the relevance of OP in ASC; instead, preferring to believe that much of the social difficulties seen in ASC are connected to lack of ToM, poor executive functioning or impaired central coherence (Happe and Frith, 2006 [20]). But, what if our accepted understanding of ToM and seeming connections to empathy were not the same thing? What if children with ASC fail to pass ToM tests due to a lack of OP?

ToM is said to mean having the ability to 'put one's self' into someone else's shoes. For example, empathy occurs when an individual can identify with another's situation enabling them to 'feel' for/with, that person, as if they were experiencing the same situation. It can be argued though, that our typical understanding of empathy is flawed. For example, a young man commits suicide. One relative says 'this is terrible, it could have been our son'. Is this empathy-identifying /sharing with the family of the deceased young man-or is this only feeling for self? The latter could be seen as a social construct echoed in empathetic statements but originating from 'self-preservation' and self-serving circumstances.

ASC individuals often fear losing a loved one or comfort item that they have developed a connection with and therefore exhibit behaviors of fear, anxiety and grief in response to the perceived loss of that item or person. We suggest that the behavior exhibited by children with autism is more closely related to a lack of OP than to a lack of ToM.

\section{COMMUNICATION AND BUILDING CONNECTION}

The above suggests that if we enable a child with ASC to build 'connection', we are enabling schemata and understanding. But, the above also implies children with ASC do not learn typically, therefore, we need to engage them via their interests (so they are motivated) and use strategies that connect them. In regards to strategies, there are tools such as: the picture system, various visual schedules, and numerous types of technology, including iPods and iPads. These tools may be useful in providing accommodations for learning and aid in communication. These tools also facilitate a smoother transition from one activity to another by providing the ASC individual with a sense of order and comfort during this change.

While the picture system may be useful in providing accommodation for the transition, it would not change the individual's lack of cognitive ability (BA Dombroski, personal communication, July 26,2014$)$. The only way to change an individual's lack of cognitive ability is to intentionally change the brain by creating new neural connections (BA Dombroski, personal communication, July 26, 2014). Intentional change occurs through repeated exposure or practice of novel tasks that strengthen neural connections involved in visual, auditory, and speed processing, short-term and longterm memory, attention, and logic and reasoning (BA Dombroski, personal communication, July 26, 2014). However, in order for learning to take place at all, the individual must be "attending" to the task. Whatever is most interesting will win the individual's attention. If the individual is most interested in a Disney princess doll, then the Disney princess doll must be incorporated into 
the novel task in order to capture the individual's interest and attention to learn a novel task. Disney characters, Lego models, video games (such as SIMMS video games), comic strip stories based upon super heroes, dinosaurs, role playing, etc. are all ideal motivators that can be used to initiate interest [9].

In NT cognition, multi-tasking comes naturally (default setting) so often the ability to notice, hold on to the information and recall it as needed is more available than in ASC where single mindedness/single focus/single processing tends to occur over and above multi-focus [6, 9]. However, particularly in ASC, when an activity, thought, or process is attached to an area of interest, it triggers GAMMA oscillations in the brain that are thought to enable cognitive processes involved in attention and memory (attention is captured, interest is held, learning/cognition takes place) [6, 9].

\section{PRE-CHOICE AND SOCIAL LEARNING}

During the formative years, strategies regarding limiting questions and increasing statements to promote compliance and being assertive rather than indecisive (on behalf of carers) are needed. Before the child can develop autonomy, the child must first learn to comply with basic commands, such as sitting, eating, and getting dressed (BA Dombroski, personal communication, July 26, 2014). Choices can be added later after the child has successfully learned to comply. For example, once the child has established a routine for sitting, eating, and getting dressed, options as to where to sit, what to eat, and what to wear can be introduced; although for the ASC child, options should be limited to no more than two choices initially so as not to overwhelm the individual with infinite options (BA Dombroski, personal communication, July 26, 2014). If too many choices are offered, a child with ASC may say, "No" or "Yes" or have a complete meltdown because there is too much information for the child to be able to process in order to come to a decision [5].

It is important to limit the number of options provided to ASC individuals so that they are able to maintain the feeling of, "I am safe; I am OK" as they continue to learn new tasks. Maintaining a sense of comfort combined with interest and attention is essential for learning to take place. According to Richards, 2012 [21], GAMMA power is scattered and in excess throughout the ASC brain, requiring a magnet or spark to fire it up. When interest occurs, attention is focused and GAMMA power is in full effect $[6,9]$.

\section{SOME FURTHER EXAMPLES}

An ASC child becomes impatient with her mother. The child calls her mother by the name of another little girl she knows from school. It seems the other little girl irritates the child during the day and when she is irritated by her mother later in the day, she is replaying those feelings and the scenario with the other little girl in her head. This is not an issue involving the lack of theory of mind, but rather a disconnection between the understanding of object permanence and generalization. The ASC child is failing to generalize and separate the irritation caused by her peer at school with the irritation she is experiencing with her mother. To generalize this understanding, the ASC child needs to know more than one person can give rise to similar emotions. The ASC child also needs to separate individuals and have different schemata for them. This requires the child to attend to a number of cues simultaneously, which is very difficult for a child with ASC to do ([9]; Koldewyn, et al. 2012 [22]; Green, 2011 [23]

\section{IDEAS TO EXPLAIN THIS}

As the ASC child becomes impatient with her mother, her recourse (currently) is to align what she feels with words to express it based upon previous experiences (e.g., the girl whose name she is using from school: she has OP in this regard). However, the feeling of irritability that is triggered by the girl at school is experienced as one and the same when later triggered by her mother, due to her inability to generalize her feelings from two different environments. It is possible that the initial experience of irritability was caused by this girl at school and because this girl repeatedly causes the ASC child feelings of irritability, those feelings have been permanently paired with the name of that girl. This could explain why whenever the ASC child experiences feelings of irritability, she calls the person causing those feelings the name of the girl at school who initiated those feelings. Role playing or watching a video of a girl becoming irritated by her peers and then positively managing her emotions would help the ASC child to generalize her feelings to other environments as well as help her to manage her own emotions.

\section{ANOTHER EXAMPLE}

Child with ASC continues to ask the same question over and over again. For example, "Are we going to eat ice cream at Grater's today, mummy?" "Are we going to eat ice cream at Grater's today, mummy?" "Are we 
going to eat ice cream at Grater's today, mummy?" . . . child's mother usually says, "Yes, we are going to eat ice cream at Grater's today, sweetie." But, even after she confirms, child will still ask, "Are we going to eat ice cream at Grater's today, mummy?" When this happens, child's mother then asks, "What did I just tell you?" "Are we going to eat ice cream at Grater's today?" and then child replies, "Yes."

With the above issue of 'echoing' the child could be learning the recipe or formula for keeping things the same because she is failing to develop OP, so, the pattern goes like this: child says: "Are we going to eat ice cream at Grater's today, mummy?" "Are we going to eat ice cream at Grater's today, mummy?" "Are we going to eat ice cream at Grater's today, mummy?" . . . Mum usually says, "Yes, we are going to eat ice cream at Grater's today." Then child says, "Are we going to eat ice cream at Grater's today, mummy?" Then, Mum says "What did I just tell you?" "Are we going to eat ice cream at Grater's today?" child then replies, "Yes." The child has established OP for this particular incident in the form of a pattern in which the only way the child can be sure that they are going to eat ice cream at Grater's is if this pattern occurs.

To help establish a different pattern, use a story to illustrate it differently; perhaps with a loved cartoon character, doll, or other favoured toy. The same type of story or intervention can be staged and filmed as often as necessary with differing scenarios. This will allow the ASC child the opportunity to review the film and learn to copy the appropriate behavior in response to a particular social/environmental situation.

\section{EXAMPLE 3}

There was a character on a children's television program who wore her hair in braided pigtails that the ASC child really seemed to like. Since first seeing this character, the child became almost obsessed with wearing her hair in braided pigtails (a form of OP). She also asked her mother to make her braids really tight because if they felt too loose the child believed they would come out, even though her braids have never actually come out (lack of OP and the understanding that if they came out they could be re-done).

It appears that the ASC child's first connection with the character in braided pigtails has permanently established that the only way to wear braided pigtails is the same way this character was wearing them. Showing pictures or video of different characters wearing their hair in a variety of braided and non- braided hairstyles would help to develop a more generalized concept of wearing one's hair in braided pigtails and that the braids could easily be redone if they came out.

As a different understanding is built for this child to help her construct more complete concepts, the need to be so rigid, to mix metaphors and to appear oppositional will diminish.

\section{CONCLUSION}

This paper has attempted to explore the possibility that ASC children do not lack theory of mind, which suggests that ASC individuals lack empathy towards others, but instead lack generalization and object permanence which makes it difficult for them to organize and manage their thoughts and emotions outside of the schemas that they have already developed. The authors of this paper believe that when interested and connected, ASC children can be deeply empathetic. The remedy for developing object permanence and generalizing concrete and abstract concepts for ASC children is to focus our efforts on their interests. Creating the same scenario in varying environments will help to establish object permanence and promote generalization. Incorporating the ASC child's interest with novel events will stimulate the attention that is needed for learning to take place.

\section{REFERENCES}

[1] American Psychiatric Association: Diagnostic and Statistical Manual of Mental Disorders, Fifth Edition. Arlington, VA, American Psychiatric Association 2013. Web. [access date: 1 June 2013]. dsm.psychiatryonline.org

[2] Belmonte MK. Abnormal attention in autism shown by steady-state visual evoked potentials. Autism 2000; 4: 269285.

http://dx.doi.org/10.1177/1362361300004003004

[3] Dern S. Autistic intelligence, autistic perception and autistic patterns of thought that we all share in different degrees - an update. Accessed Jan. 31, 2013. www.autismand computing.org.uk

[4] Harmon K. Autism might slow brain's ability to integrate input from multiple senses. Scientific American August 2010; 21: 19.

[5] Lawson W. Life Behind glass London: JKP 2000.

[6] Lawson W. The passionate mind: How individuals with autism learn. Jessica Kingsley: London 2011.

[7] Murray DKC. Attention tunneling and autism. In P. Shattock \& G. Linfoot (Eds.), Living with autism: The individual, the family and the professional Sunderland: Autism Research Unit, University of Sunderland 1992; pp. 89-97.

[8] Murray DKC, Lesser M, Lawson W. Attention, monotropism and the diagnostic criteria for autism. Autism 2005; 9(2): 139156.

http://dx.doi.org/10.1177/1362361305051398

[9] Lawson W. Sensory connection, interest/attention and GAMMA synchrony in autism: Brain connections and 
preoccupation'. Medical Hypothesis: Elsevier (Dec 27. pii: S0306-9877(12)00541-5, 2012.

http://dx.doi.org/10.1016/j.mehy.2012.12.005

[10] Baillargeon R, DeVos J. Object permanence in young infants: further evidence. Child Development 1991; 62(6).

[11] Björne p. A possible world: Theory to practice. In Lund University Cognitive Studies 2007; 134. http://raisingchildren. net.au/articles/autism_spectrum_disorder_attention.html

[12] McLeod SA. Sensorimotor Stage 2010. Retrieved from: http://www.simplypsychology.org/sensorimotor.html

[13] Parrot W. Emotions in Social Psychology, Psychology Press, Philadelphia 2001.

[14] Grace E. Object Permanence and Infants' Accessed: January, 2015. http://www.kidsdevelopment.co.uk/ objectpermanenceinfants.html

[15] LeDoux J. The Emotional Brain: The Mysterious Underpinnings of Emotional Life. New York: Simon and Schuster 1998

[16] Klin A, Jones W, Schultz R, Volkmar F. The enactive mind or from actions of cognition: Lessons from autism. Philosophical
Transactions of the Royal Society of London. Series B, Biological Sciences 2003; 358: 345-360. http://dx.doi.org/10.1098/rstb.2002.1202

[17] Young J, Klosko J, Weishaar S. Schema Therapy: A Practitioner's Guide. New York: The Guilford Press 2003.

[18] http://www.csus.edu/indiv/g/gipej/teaparty.pdf

[19] Happe F, Frith U. The weak coherence account: Detailfocused cognitive style in autism spectrum disorders. Journal of Autism and Developmental Disorders 2006; 36(1): 5-25. http://dx.doi.org/10.1007/s10803-005-0039-0

[20] Richards AE. Gamma oscillatory activity in autism spectrum disorder during a gaze cueing task, Eastern Michigan University Digital Commons @ EMU 2012.

[21] Koldewyn K, Weigelt S, Kanwisher N, Jaing Y. 'Multiple Object Tracking in Autism Spectrum Disorders.' Journal of Autism and Developmental Disorders 2012 http://dx.doi.org/10.1007/s10803-012-1694-6

[22] Green R. 2011. www.livesinthebalance.org https://www. youtube.com/watch?v=uoXBFOZml80 